\title{
APPLYING THE ANALYTIC HIERARCHY PROCESS (AHP) TO BUILD A STRATEGIC FRAMEWORK FOR TECHNOLOGY ROADMAPPING
}

\author{
Nathasit Gerdsri, Dundar F. Kocaoglu \\ Department of Engineering and Technology Management \\ Maseeh College of Engineering and Computer Science \\ Portland State University, Portland, OR 97201 \\ nathasitg@etm.pdx.edu, kocaoglu@etm.pdx.edu
}

Keywords: Technology Roadmapping, Technology Planning, Technology Evaluation, AHP

Summary: The development of a new concept called Technology Development Envelope (TDE) is presented in this paper. The TDE is developed to transform the technology roadmapping approach to the level in which it is dynamic, flexible, and operationalizable. This new approach provides an effective way to help organizations to overcome the challenge of keeping a roadmap alive. The paper emphasizes how the AHP is applied as a part of the TDE framework.

\section{Introduction}

Technology roadmapping is a comprehensive approach to strategic planning for the integration of science/technology development into product and business aspects. Since its earlier introduction, as a concept, by Robert Galvin, a former Motorola chairman, in the late 1970s, technology roadmapping has been evolving as a new practice in technology management (Willyard and McClees 1987). Currently, the roadmapping concept is widely adopted in industry, government, and academia for providing a way to develop a technology strategy, identify gaps and opportunities in research development, and plan for resource allocation (Albright and Kappel 2003; Probert 2003; Kostoff, Robert Boylan et al. 2004; Richey and Grinnell 2004; Wells, Phaal et al. 2004).

The results of technology roadmapping are presented in a time-based format with multi-layers linking technology-related issues to business decisions. The system thinking approach must be applied to the analysis to capture the change of elements-business, markets, products, technology, $\mathrm{R} \& \mathrm{D}$, and recourses — and the impacts of those changes on an organization over time.

Under the fast-changing environment in business and technology development, the roadmapping approach should have dynamic and flexibility features so that organizations can reassess and adjust their roadmaps in a timely manner according to the impacts of the changes. By enhancing dynamic and flexibility features, it would help overcome the key challenge in implementing roadmapping which technology managers and practitioners are facing in terms of "keeping a roadmap alive" as identified in the survey results conducted by the Institute of Manufacturing, University of Cambridge (Phaal, Farrukh et al. 2001).

This paper presents a new concept and methodology called Technology Development Envelope (TDE) for transforming the roadmapping approach to the level in which it is dynamic, flexible, and most importantly, operationalizable.

The TDE approach helps the executive level decision makers in corporations and the policy level decision makers in governments to incorporate disruptive technologies and radical innovations in the development of technology strategies. The outcome of TDE analysis is the optimum path of 
technology development which an organization should follow in order to maximize its technological benefits (Gerdsri 2005).

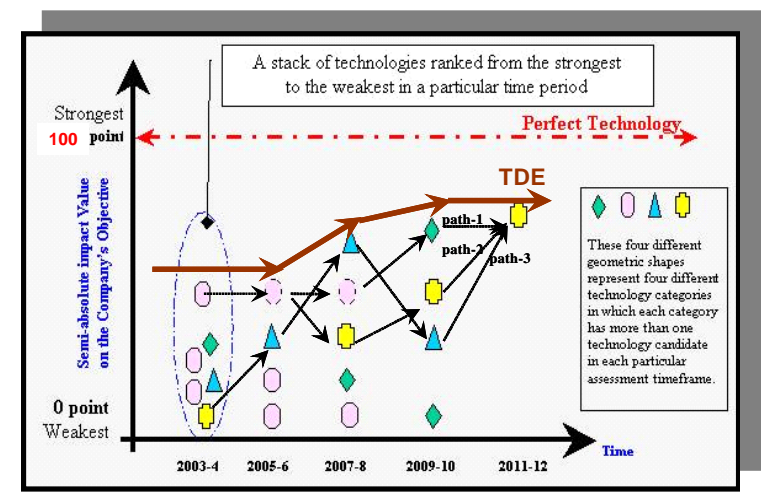

Figure 1: TDE Diagram

\section{TDE Framework for Roadmapping a Technology}

The concept of TDE is to link technology to organization strategy so that managers can understand where technologies are going in the future while comprehending how technologies fit into their organization strategy.

The TDE framework is structured by obtaining strategic information on the development of technologies and then using this information to evaluate the value of each technology based on the impacts of its characteristics on the organization's objective in each time period. A technology development envelope is formed by connecting technologies that have the highest value in each period throughout the specified timeframe.

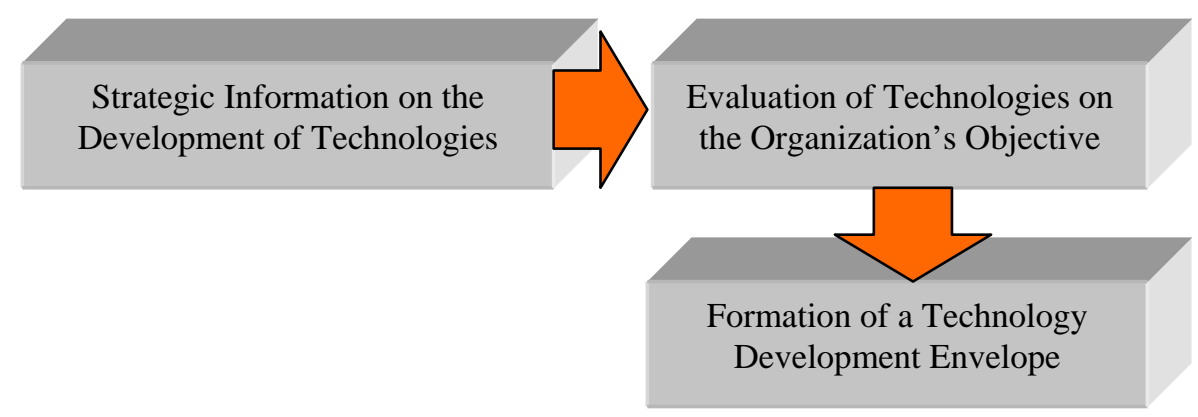

Figure 2: A TDE Framework

Delphi method and Analytic Hierarchy Process (AHP) are combined as two parts of the TDE framework. Delphi method is used for obtaining the strategic information about the future development of technologies from a group of experts involved in developing technologies. AHP is used for evaluating the impacts of technologies on an organization's objective. A series of judgment quantifications is obtained from a group of experts within an organization involved in implementing any new technology and integrating them into products. 


\section{Integrating AHP into the TDE Framework}

AHP is a comprehensive framework designed to cope with the intuitive, the rational, and the irrational when decision makers make multi-objective, multi-criterion and multi-factor decisions with or without certainty about any number of alternatives (Harker and Vargas 1987). The AHP approach was designed to help decision makers incorporate qualitative (intangible) and quantitative (tangible) aspects of a complex problem. It systematically solves complex problems by decomposing the structure of a problem into hierarchies and then applies the pairwise comparison judgment to develop priorities in each hierarchy. After Thomas Saaty first introduced AHP in 1976, the concept has gradually evolved through a number of applications as diverse as energy allocation, marketing decisions, project selection and evaluation, technology selection, new product screening, and conflict resolution.

In the technology management area, there have been several studies done on applying the AHP approach to the evaluation or assessment of technologies: "Technological Choice in the Less Developed Countries: An Analytical Hierarchy Approach” (Ramanujam and Saaty 1981); "The Analytical Hierarchy Process for Choice of technologies" (Prasad and Somasekhara 1990); "The Prioritization of Technologies in a Research Laboratory" (Melachrinoudis and Rice 1991); "Prioritizing Telecommunications Technologies for Long-Range R\&D Planning to the Year 2006" (Suh, Suh et al. 1994); and "Justification of New Manufacturing Technology: A Strategic Approach Using the AHP” (Albayrakoglu 1996).

In those studies, the hierarchical model for the evaluation and assessment of technologies is constructed with either 3 levels (objective-criteria-technology alternatives) or 4 levels (objectivecriteria-subcriteria-technology alternatives). The series of comparative judgments is analyzed to determine the relative impact of technologies on the objective. The results are represented as a relative value indicating how many times one technology is better than the other alternatives.

However, to enhance dynamic and flexibility features of the TDE framework used for technology roadmapping, the conventional approach of structuring a hierarchical decision model with the technology alternatives at the lowest level as shown in Figure 3 is not rigorous since the whole series of comparative judgments needs to be repeated every time a change in the development of any particular technology is captured or a new technology emerges.

A new structure of a hierarchical model approach as shown in Figure 4 is proposed by replacing technology alternatives at the lowest level with their measures of effectiveness.

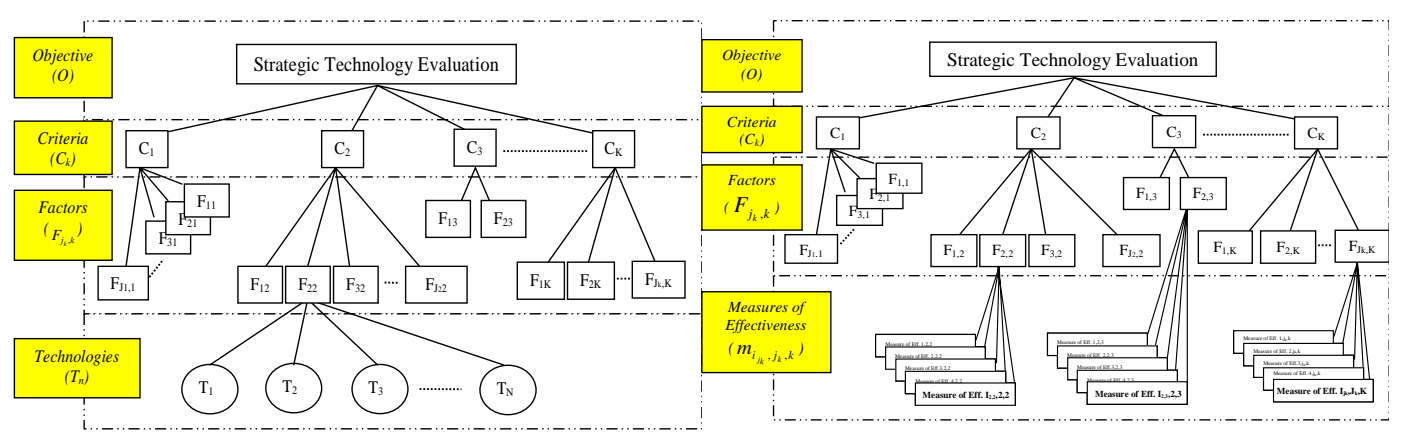

Figure 3: A Conventional Hierarchical Model Using a Relative Value Measurement
Figure 4: A Proposed Hierarchical Model Using a Semi-absolute Value Measurement 
Each technology is evaluated based on the degree to which its characteristic metrics [ $t_{n, j_{k}, k}$ ] satisfy an organization's desirability on the measures of effectiveness of each metric [ $m_{i_{j_{k}}, j_{k}, k}$ ]. Then, the desirability values $\left[V\left(t_{n, j_{k}, k}\right)\right.$ ] are factored with the relative importance of factors associated with each criterion [ $f_{j_{k}, k}$ ] and the relative priority of criteria on the objective [ $w_{k}$ ].

With this approach, technologies are evaluated on the semi-absolute values instead of the relative values. The mathematical model supporting the evaluation of technologies is shown below.

$$
T V_{n}=\sum_{k=1}^{K} \sum_{j_{k}=1}^{J_{k}} w_{k} \cdot f_{j_{k}, k} \cdot V\left(t_{n, j_{k}, k}\right)
$$

where

$\mathrm{TV}_{\mathrm{n}}$ : $\quad$ Technology value of technology (n) determined according to a company's objective

$w_{k}$ : $\quad$ Relative priority of criterion (k) with respect to the company objective

$f_{j_{k}, k}: \quad$ Relative importance of factor $\left(\mathrm{j}_{\mathrm{k}}\right)$ with respect to criterion $(\mathrm{k})$

$\sum_{j_{k}=1}^{J_{k}} w_{k} \cdot f_{j_{k}, k} \quad:$ Relative importance of factor $\left(\mathrm{j}_{\mathrm{k}}\right)$ with respect to the objective

$t_{n, j_{k}, k}$ : $\quad$ Performance and physical characteristics of technology (n) along with factor $\left(\mathrm{j}_{\mathrm{k}}\right)$ for criterion (k)

$V\left(t_{n, j_{k}, k}\right)$ : Desirability value of the performance and physical characteristics of technology (n) along factor $\left(\mathrm{j}_{\mathrm{k}}\right)$ for criterion $(\mathrm{k})$

As a result, the value of technology indicates the degree to which each technology exclusively satisfies an organization's objective. The ideal technology from an organization's point of view would represent the value of 100 .

By tracking the development progress of each technology over time, the changes on the value of technology would represent the degree to which an organization perceives the values on the improvement of technologies.

The development of the AHP model is achieved in three steps: 1) technology characterization, 2) hierarchical modeling, and 3) technology evaluation as shown in Figure 5. The processes of identifying components and quantifying the relative importance of components in each hierarchy can be completed by a group of experts in an organization involved in the processes of implementing technologies. 


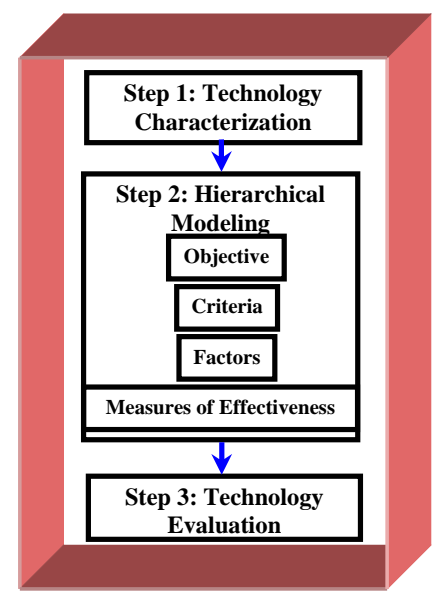

Figure 5: Process of Building AHP Model

\section{A Case Study - AHP Modeling for the TDE Framework}

In this case study, the TDE approach was applied to help one of the leading computer server developers determine an optimal path for the development of electronic cooling technologies in which the company's technological competitiveness would be maximized. All data presented in this case are the actual data collected from experts in the fields, but due to confidentiality and propriety issues, the identities of experts participating in this research can not be revealed. (All data were collected during January -March 2004.)

The following section describes how the AHP model was built according to the three steps as described above:

\subsection{AHP Modeling}

\subsubsection{Step 1: Technology Characterization}

The group of experts in the company defined their objective for technology evaluation as "to achieve technological competitiveness from new thermal platform development for computer servers." Seven criteria and factors associated with each criterion along with their limiting values on the measure of effectiveness were finalized as listed in Table 1. 
Table 1: Hierarchical Structure

\begin{tabular}{|c|c|c|}
\hline Objective & Criterion & Factors \\
\hline \multirow{4}{*}{$\begin{array}{l}\overline{\widetilde{\sigma}} \\
\frac{E}{0} \\
\stackrel{E}{F}\end{array}$} & \multirow{3}{*}{ C1: Performance } & F11: Heat removal flux \\
\hline & & F21: Thermal resistance \\
\hline & & F31: Temperature controllability \\
\hline & \multirow{4}{*}{$\begin{array}{l}\text { C2: } \\
\text { Geometric }\end{array}$} & F12: Height \\
\hline \multirow{4}{*}{ 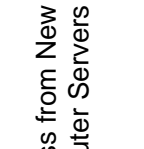 } & & F22: Footing space \\
\hline & & F32: Weight \\
\hline & & F42: Distance of heat transportation \\
\hline & \multirow{5}{*}{$\begin{array}{l}\text { C3: } \\
\text { Reliability }\end{array}$} & F13: Continuous operation \\
\hline \multirow{5}{*}{ 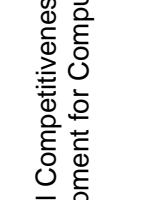 } & & F23: Durability under adverse environment conditions \\
\hline & & F33: \% of performance drop overtime \\
\hline & & F43: Length of the warming up period at start \\
\hline & & F53: Longevity \\
\hline & \multirow{3}{*}{$\begin{array}{l}\text { C4: } \\
\text { Economic }\end{array}$} & F14: Power consumption for cooling system \\
\hline \multirow{9}{*}{ 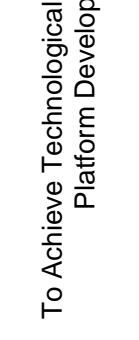 } & & F24: Cost of fabrication \\
\hline & & F34: Cost for recharging, servicing and reclamation \\
\hline & \multirow{2}{*}{$\begin{array}{l}\text { C5: Environmental } \\
\text { Compatibility }\end{array}$} & F15: Toxic control of cooling media and combustion products \\
\hline & & F25: Temperature control of exhausted coolant (air/gas/liquid) \\
\hline & \multirow{2}{*}{$\begin{array}{l}\text { C6: Serviceability and } \\
\text { Maintenance }\end{array}$} & F16: Installation \& maintenance Complexity \\
\hline & & F26: Interchangeability of components \\
\hline & \multirow{3}{*}{$\begin{array}{l}\text { C7: } \\
\text { Flexibility }\end{array}$} & F17: Physical Moldability \\
\hline & & F27: Scalability \\
\hline & & F37: Upgradeability \\
\hline
\end{tabular}

\subsubsection{Step 2: Hierarchical Modeling}

Experts provided their comparative judgments for each pair of criteria and factors. The inputs were analyzed to determine the relative priority of criteria as well as the relative importance of factors associated with each criterion. The results indicate that among seven criteria, the experts placed their emphasis on performance, reliability, and economic aspect driving their technological competitiveness as shown in Table 3. This result also reflects the company's mission in maintaining its appearance as a performance leader in this sector. The relative importance of factors under each criterion was also calculated. The results are also presented in Table 3.

The desirability curves representing the company's preference for the technological metrics of each factor were developed. Figure 6 shows some examples of desirability curves developed for heat removal flux, longevity, cost of fabrication, and upgradeability factors. 

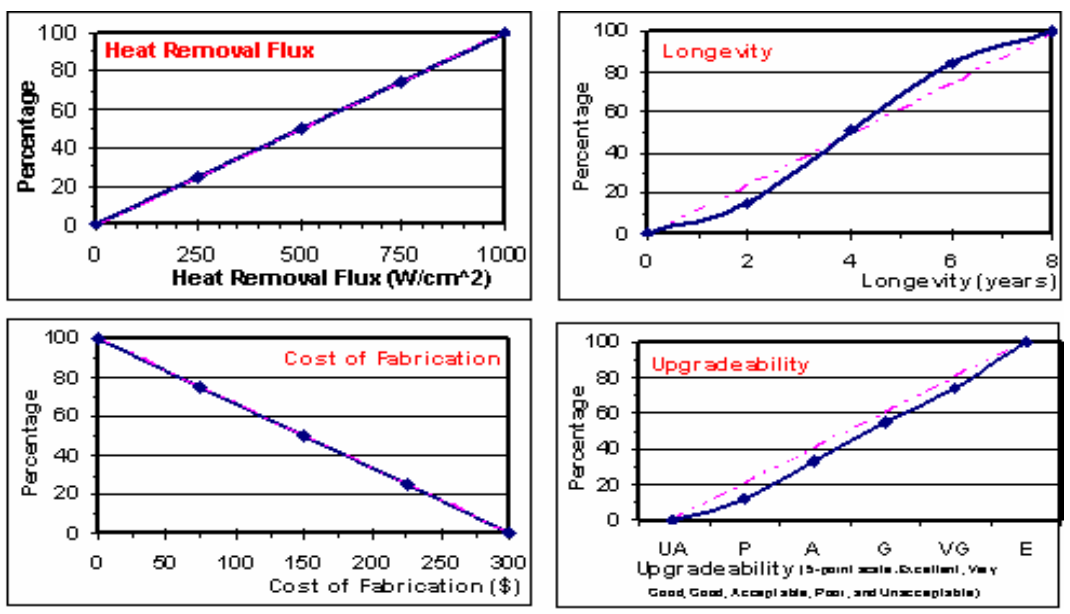

Figure 6: Desirability Curves

\subsubsection{Step 3: Technology Evaluation}

Each technology was evaluated in each time period by measuring how well their technological metrics meet the company's desirability level and then factoring that by the relative importance of factors and the relative priority of criteria.

The strategic information about the future development of electronic cooling technologies was obtained from the group of technology developers in the field. Sixteen technologies were included as potential technologies from 2004 to 2010. The development progress of each technology was estimated by experts along twenty-two factors throughout the specified period.

For example, a group of experts agreed that Jet-Impingement and Spray Cooling technology (T6) would be ready for OEM's implementation in 2004-5. Experts also indicated that the current performance, physical, and economical characteristics of this technology are expected to be significantly improved over the specified time period. As shown in Table 2, the heat removal flux is expected to improve by 5 times from the current level of $200 \mathrm{~W} / \mathrm{cm}^{2}$ to $1000 \mathrm{~W} / \mathrm{cm}^{2}$ in 2010 . The height of the main components will be reduced by half from 0.5 inch in 2004-5 to 0.25 inch in 20089. The current length of the warming-up period will be dramatically shortened from 60 to 10 seconds by 2008-2009, and the current cost of fabrication is expected to drop from $\$ 80$ to $\$ 50$ to $\$ 25$.

Table 3 shows the computation of technology value of Jet-impingement and Spray Cooling Technology $\left(\mathrm{T}_{6}\right)$ in 2004-5. As the development of this technology continues, its value would be improved by $30 \%$ in 2010 as shown in Figure 7. 
Table 2: Technological Metrics of Jet-impingement and Spray Cooling Technology

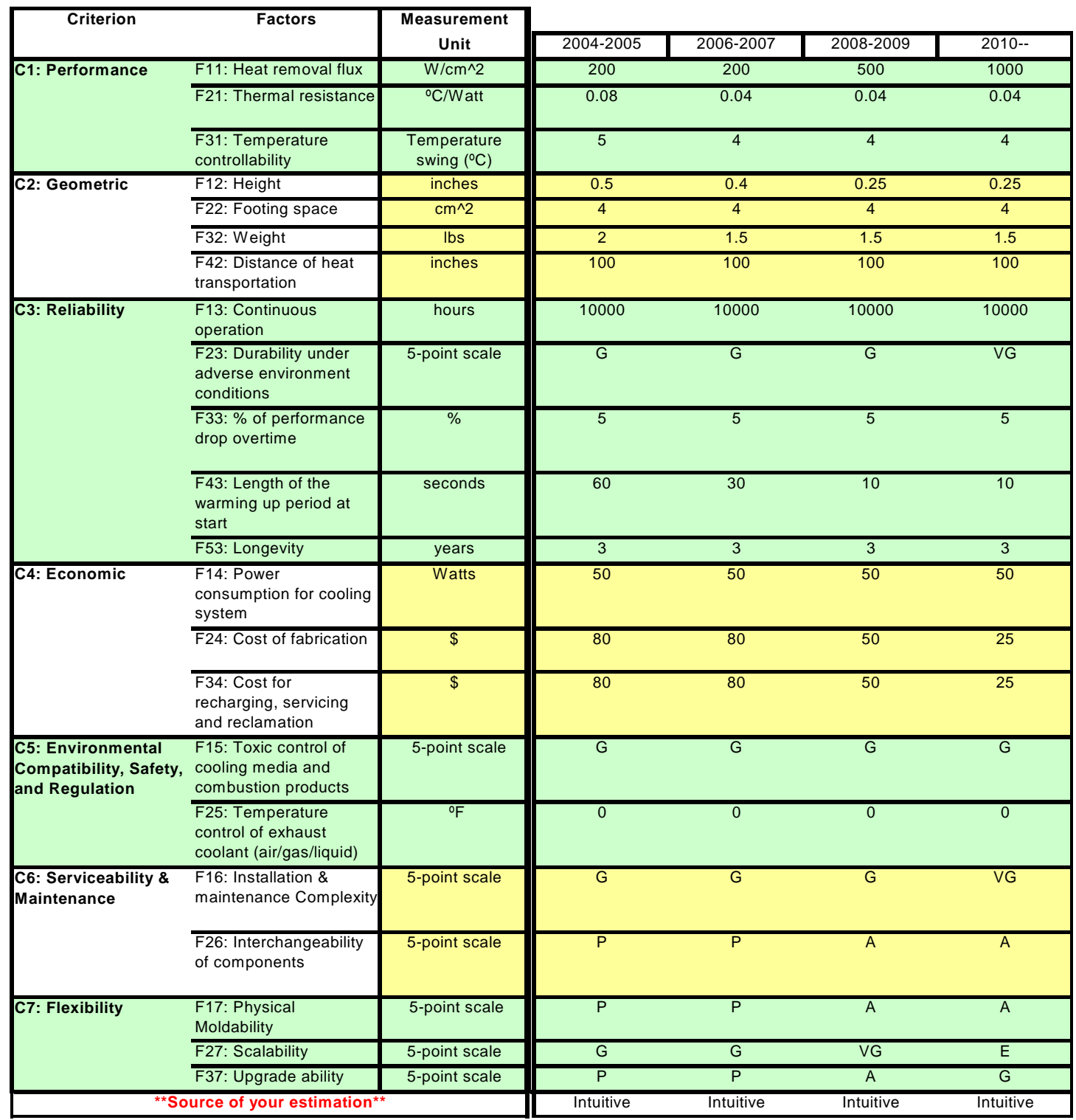

Remark: E (excellent); VG (very good); G (good); A (acceptable); P (poor); UA (unacceptable) 
Table 3: Computation of the Technology Value of Jet-impingement and Spray Cooling Technology

\begin{tabular}{|c|c|c|c|c|c|c|}
\hline \multicolumn{2}{|l|}{ Criterion } & \multirow[t]{2}{*}{ Factors } & & \multirow{2}{*}{ Metrics } & $\begin{array}{l}\text { Desirability } \\
\text { Value }\end{array}$ & \multirow{2}{*}{$\begin{array}{l}\text { Technology } \\
\text { Value }\end{array}$} \\
\hline & $w_{k}$ & & $f_{j_{k}, k}$ & & $V\left(t_{n, j_{k}, k}\right)$ & \\
\hline \multirow{3}{*}{$\begin{array}{l}\text { C1: } \\
\text { Performance }\end{array}$} & \multirow{3}{*}{0.27} & F11: Heat removal flux & 0.34 & 200 & 20 & 1.84 \\
\hline & & F21: Thermal resistance & 0.46 & 0.08 & 74.7 & 9.28 \\
\hline & & $\begin{array}{l}\text { F31: Temperature } \\
\text { controllability }\end{array}$ & 0.2 & 5 & 54.7 & 2.95 \\
\hline \multirow{4}{*}{$\begin{array}{l}\text { C2: } \\
\text { Geometric }\end{array}$} & \multirow{4}{*}{0.12} & F12: Height & 0.33 & 0.5 & 94.1 & 3.73 \\
\hline & & F22: Footing space & 0.35 & 4 & 75.0 & 3.15 \\
\hline & & F32: Weight & 0.16 & 2.0 & 0.0 & 0.00 \\
\hline & & $\begin{array}{l}\text { F42: Distance of heat } \\
\text { transportation }\end{array}$ & 0.16 & 100 & 100.0 & 1.92 \\
\hline \multirow{5}{*}{$\begin{array}{l}\text { C3: } \\
\text { Reliability }\end{array}$} & \multirow{5}{*}{0.2} & F13: Continuous operation & 0.22 & 10000 & 40.8 & 1.79 \\
\hline & & $\begin{array}{l}\text { F23: Durability under adverse } \\
\text { environment conditions }\end{array}$ & 0.2 & G & 69.0 & 2.76 \\
\hline & & $\begin{array}{l}\text { F33: \% of performance drop } \\
\text { overtime }\end{array}$ & 0.22 & 5 & 95.0 & 4.18 \\
\hline & & $\begin{array}{l}\text { F43: Length of the warming } \\
\text { up period at start }\end{array}$ & 0.14 & 60 & 46.9 & 1.31 \\
\hline & & F53: Longevity & 0.22 & 3 & 31.7 & 1.39 \\
\hline \multirow{3}{*}{$\begin{array}{l}\text { C4: } \\
\text { Economic }\end{array}$} & \multirow{3}{*}{0.15} & $\begin{array}{l}\text { F14: Power consumption for } \\
\text { cooling system }\end{array}$ & 0.52 & 50 & 50.0 & 3.90 \\
\hline & & F24: Cost of fabrication & 0.23 & 80 & 73.3 & 2.53 \\
\hline & & $\begin{array}{l}\text { F34: Cost for recharging, } \\
\text { servicing and reclamation }\end{array}$ & 0.25 & 80 & 73.3 & 2.75 \\
\hline \multirow{2}{*}{$\begin{array}{l}\text { C5: } \\
\text { Environmental } \\
\text { Compatibility }\end{array}$} & \multirow{2}{*}{0.09} & $\begin{array}{l}\text { F15: Toxic control of cooling } \\
\text { media and combustion } \\
\text { products }\end{array}$ & 0.54 & G & 60.0 & 2.92 \\
\hline & & $\begin{array}{l}\text { F25: Temperature control of } \\
\text { exhausted coolant } \\
\text { (air/gas/liquid) }\end{array}$ & 0.46 & 0 & 100.0 & 4.14 \\
\hline \multirow{2}{*}{$\begin{array}{l}\text { C6: } \\
\text { Serviceability } \\
\text { and } \\
\text { Maintenance }\end{array}$} & \multirow{2}{*}{0.09} & $\begin{array}{l}\text { F16: Installation \& } \\
\text { maintenance Complexity }\end{array}$ & 0.45 & G & 60.0 & 2.43 \\
\hline & & $\begin{array}{l}\text { F26: Interchangeability of } \\
\text { components }\end{array}$ & 0.55 & $\mathrm{P}$ & 23.0 & 1.14 \\
\hline \multirow{3}{*}{$\begin{array}{l}\text { C7: } \\
\text { Flexibility }\end{array}$} & \multirow{3}{*}{0.08} & F17: Physical Moldability & 0.24 & $\mathrm{P}$ & 10.0 & 0.19 \\
\hline & & F27: Scalability & 0.4 & G & 56.4 & 1.81 \\
\hline & & F37: Upgradeability & 0.36 & $P$ & 14.6 & 0.42 \\
\hline & & & & & & 56.53 \\
\hline
\end{tabular}




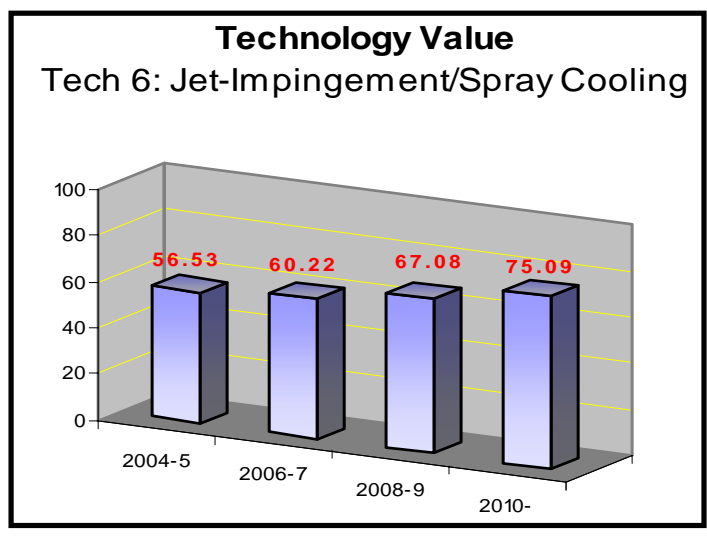

Figure 7: Improvement of the value of Jet-Impingement/Spray Cooling Technology over time

\subsection{Formation of a Technology Development Envelope}

By combining the evaluation results of all sixteen technologies in each two-year period from 2004 to 2010, the changes in the technology value of all sixteen technologies are graphically presented in Figure 8.

From the technology evaluation results, a technology development envelope (TDE) can be formed as a path connecting Pool Boiling (T5) in 2003, Capillary Pumped Loops Heat Pipes (T11) in 2004-5, Mechanically Pumped Single-Phase Liquid Cooling (N1) in 2006-7, and Jet-impingement and Spray Cooling (T6) from 2008-10 since the value of these four technologies is the highest in those periods.
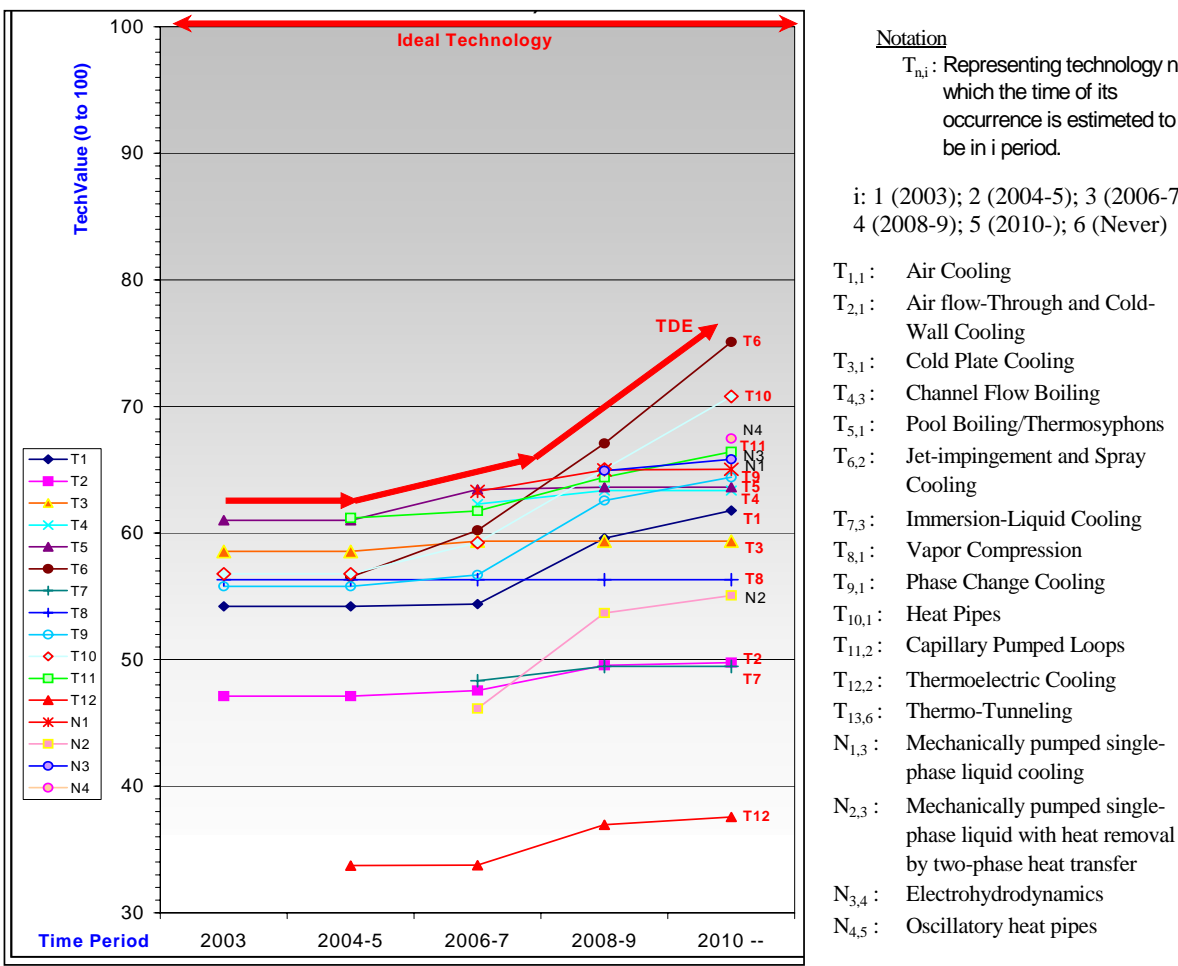

$\mathrm{N}_{4,5}$ : Oscillatory heat pipes

Figure 8: Position of technologies ranked by their impact values on the company's objective 


\section{Conclusions}

The technology roadmapping approach is strengthened by introducing flexibility, dynamic, and operationalizeability features into the analysis through the development of the Technology Development Envelope concept. The application of AHP allows the impacts of technology to be measured in both intangible and tangible ways. With a modified AHP approach applied to the TDE framework, the value of technologies can be re-evaluated or quantified in almost no time in three different ways as: 1) the changes on the development of any particular technology are captured; 2) new technologies emerge; 3 ) the variations in a company's priorities are identified. Then, the TDE diagram would be automatically adjusted to reflect those changes.

\section{References EN.REFLIST}

